\title{
Presentation, acute illness, and learning difficulties in salt wasting 21-hydroxylase deficiency
}

\author{
Malcolm D C Donaldson, Paul H Thomas, Janet G Love, Gordon D Murray,
} Andrew W McNinch, Denis C L Savage

\begin{abstract}
The presentation, pattern of acute illness, and incidence of learning difficulties are described in 63 (33 boys, 30 girls) children with salt wasting 21-hydroxylase deficiency, drawn from a cohort study of congenital adrenal hyperplasia in the South West Region of England between 1968 and 1988. Thirty boys presented with a salt losing crisis from birth whereas the other three boys presented between 2 and 14 months of age with failure to thrive and hyponatraemia. Diagnostic uncertainty led to $13(43 \%)$ of 30 girls developing a salt losing crisis. Five girls were misassigned as boys at birth. There were four deaths in the group, two due to salt losing crisis, one to complications of prematurity possibly compounded by 21-hydroxylase deficiency, and one from heart failure probably related to an excess of steroids. Acute admissions were common, especially during the first year of life, with convulsions in $7 \%$ of admissions. The $9 \%$ incidence of hypoglycaemia was considered to be an underestimate as blood glucose was measured in only $56(22 \%)$ of 254 admissions. No convulsions occurred in the $38(15 \%)$ admissions where the parents had given intramuscular hydrocortisone before bringing the child to hospital. A high incidence of learning difficulties was found among the 59 surviving children $(9 / 30(30 \%)$ boys and $6 / 29(21 \%)$ girls), and in only two children could any factor other than 21-hydroxylase deficiency be invoked. Analysis of the subgroup with learning difficulties indicated that they were more ill at presentation with a significantly higher incidence of hypoglycaemia, and that growth in the first year was significantly worse.

It is concluded that congenital adrenal hyperplasia remains a formidable disorder with an appreciable mortality and morbidity. The high incidence of learning difficulties seen in salt wasting 21-hydroxylase deficiency needs further attention. A prospective study is indicated to examine the effect of neonatal screening on morbidity from congenital adrenal hyperplasia, particularly the intellectual impairment seen in this study.

(Arch Dis Child 1994; 70: 214-218)
\end{abstract}

21-Hydroxylase deficiency is by far the most common cause of congenital adrenal hyperplasia. The presentation varies according to the severity of the enzyme defect and the sex of the child. Boys with a severe defect present during the neonatal period with dehydration, hyponatraemia, hyperkalaemia, and hypoglycaemia due to glucocorticoid and mineralocorticoid insufficiency - the salt losing crisis. Girls with a severe defect present with ambiguous genitalia at birth due to the effects of excess androgen in utero, and they progress to a salt losing crisis unless they are promptly diagnosed and treated. This type of 21-hydroxylase deficiency is termed salt losing or salt wasting, whereas the milder defect without manifest salt loss is termed the simple virilising variety.

Since the first description of cortisone treatment in congenital adrenal hyperplasia ${ }^{1}$ the clinical course of treated patients has been well documented in terms of growth ${ }^{23}$ and final height prognosis, ${ }^{45}$ while there are some data on psychosexual function ${ }^{67}$ and fertility. ${ }^{58}$ Although adrenal decompensation in the face of acute illness is a notoriously common event in salt wasting 21-hydroxylase deficiency, this aspect of the disorder has not been formally studied. Moreover, a link between salt wasting 21-hydroxylase deficiency and significant learning difficulties is not widely recognised.

We present here a cohort of children with salt wasting 21-hydroxylase deficiency who received part or all of their care in a geographically defined area over a 20 year period. We describe the presentation and pattern of acute illness in early childhood, the learning difficulties evident in a substantial minority of these children, and examine the possible relation between intellectual impairment, perinatal events, and acute illness.

\section{Patients and methods}

The children are drawn from a retrospective cohort study conducted on all patients with congenital adrenal hyperplasia born between January 1968 and January 1988, who received part or all of their care in the South West Region of England. The diagnosis of 21-hydroxylase deficiency was made from the clinical presentation of the subjects with salt losing crisis or ambiguous genitalia, or both, together with biochemical confirmation either by 17-hydroxyprogesterone measurement or by measurement of steroids in urine (usually 11-oxygenation index or pregnanetriol 
estimation) in the earlier years. Details of birth, mode of presentation, intercurrent illness, weight and height, and treatment were recorded. Virilisation in the girls was staged as described by Prader. ${ }^{9}$ The presence and severity of learning difficulties was assessed by a questionnaire completed by the paediatrician caring for the child about the type of school attended, the need for remedial help, and the existence of behaviour problems requiring specialist help. Heights at 1 year of age were expressed as standard deviation (SD) scores using the formula (height-mean height for age)/SD height for age.

\section{Results}

Sixty three subjects ( 30 girls and 33 boys) with salt wasting 21-hydroxylase deficiency were identified among the cohort of 80 children with congenital adrenal hyperplasia. Their mean (SD) age was $9 \cdot 4(5 \cdot 6)$ years with a range of 0.2 to 18.9 years. The mean (SD) birth weights of the 33 boys and 30 girls was 3530 (610) and 3300 (530) g respectively. The mean (range) gestation was 40 (33-42) weeks, with only four births occurring before 37 completed weeks. One infant had respiratory distress syndrome and one had congenital heart disease requiring surgery, but otherwise there were no significant neonatal problems other than those related to congenital adrenal hyperplasia.

\section{PRESENTATION}

Nineteen $(63 \%)$ of the 30 girls were diagnosed clinically at birth (figure) because of ambiguous genitalia; 12 of these developed biochemical evidence of salt loss (sodium less than $130 \mathrm{mmol} / \mathrm{l}$ or potassium greater than 7.5 $\mathrm{mmol} / \mathrm{l}$, or both) before starting treatment, with frank salt losing crisis occurring in four. In a further six girls born between 1970 and 1979 ambiguous genitalia were noted at birth but congenital adrenal hyperplasia was diagnosed late (by measuring steroids in urine in four infants). All these infants developed salt losing crises (median age 9 days, range 5-22). Five girls were misassigned as boys and all manifested salt loss biochemically, with frank

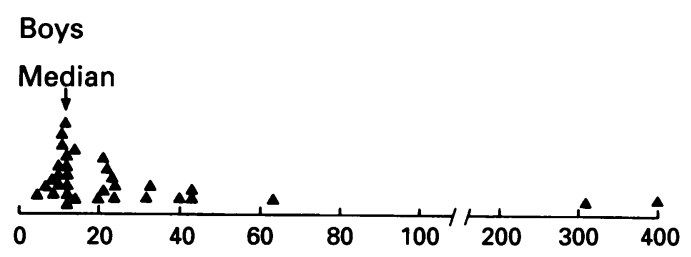

Girls

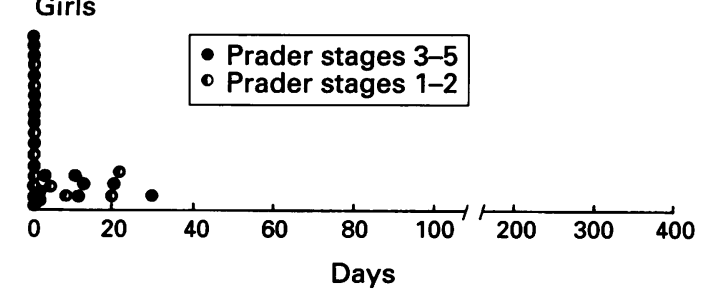

Age of diagnosis in 33 boys and 30 girls with salt wasting 21-hydroxylase deficiency. crisis in three. The median age of salt losing crisis in all 13 girls was 12 days (range 9-33).

Thirty $(91 \%)$ of the 33 boys presented with a salt losing crisis before 6 weeks of age with a median age at hospital admission of 12 days (range 5-42). The remaining three boys presented later at 2,11 , and 14 months of age with failure to thrive, hyponatraemia, and constipation. These infants were presumed to have a milder 21-hydroxylase defect.

The common symptoms in the 56 children (23 girls and 33 boys) showing biochemical evidence of salt loss included vomiting (29 $(52 \%))$, poor feeding $(30(54 \%))$, and poor weight gain or weight loss $(42(75 \%))$. Pigmentation of the labia or scrotum was recorded in $23(41 \%)$ patients, but often in retrospect only. Mean plasma sodium was $120.5 \mathrm{mmol} / \mathrm{l}$ (range (SD) $100-140$ (9)) and plasma potassium $7.9 \mathrm{mmol} / 1$ (range (SD) $5 \cdot 7-13 \cdot 3(1 \cdot 2)$ ). Blood glucose (available in only 20 patients) was $3.2 \mathrm{mmol} / \mathrm{l}$ (range (SD) $0.5-6.6(1.8))$, nine $(16 \%)$ infants showing frank hypoglycaemia $(0.5-2 \cdot 0 \mathrm{mmol} / \mathrm{l})$.

There were three early and one late infant deaths. Two boys died, in 1968 and 1975, from salt losing crisis. Another boy born at 33 weeks' gestation in 1984 deteriorated on day 5 while receiving care for suspected necrotising enterocolitis and respiratory distress syndrome, but the diagnosis of congenital adrenal hyperplasia was not made until 21 days. He was subsequently found to have spastic quadriplegia and died aged 7 months. The fourth death was a girl who presented at 34 weeks' gestation with ambiguous genitalia and a diagnostic increase in plasma 17-hydroxyprogesterone. She developed respiratory distress syndrome and died on day 9 from heart failure after receiving large doses of glucocorticoids, daily doses ranging between 400 and 1500 $\mathrm{mg} / \mathrm{m}^{2}$ of hydrocortisone or equivalent. A necropsy showed no evidence of congenital heart disease and her heart failure was assumed to be mainly related to the use of steroids.

\section{ACUTE ILLNESS}

An attempt was made to separate acute illness into two categories: acute adrenal insufficiency related either to undertreatment, intercurrent illness, or both; and illness related to glucocorticoid, mineralocorticoid, or fluid excess.

Thirty two $(54 \%)$ of the 59 surviving children were admitted as emergencies during the first year of life with a total of 90 admissions. After the first year there were 164 admissions of 40 children. Only six $(11 \%)$ of the 57 children who were over 1 year of age by the end of the study period had not been admitted to hospital at some stage. Common symptoms included fever, vomiting, poor feeding, and diarrhoea. Fludrocortisone had been inappropriately reduced or stopped one month previously in three children and hydrocortisone or cortisone acetate had been reduced in two children, usually because the diagnosis of 21-hydroxylase deficiency was in doubt.

Hypoglycaemia (blood glucose less than $2.5 \mathrm{mmol} / \mathrm{l})$ was documented in $24(9 \%)$ 
admissions (14 patients). Blood glucose had been measured in only $66(26 \%)$ of the 254 acute episodes. Of $19(7 \%)$ admissions with convulsions (15 patients) blood glucose was not measured in seven convulsions, was normal in four convulsions (all associated with fever), and showed hypoglycaemia in the remaining eight convulsions (five patients). No convulsion was recorded in the $38(15 \%)$ admissions ( 25 patients) where the parents had given intramuscular glucocorticoids before bringing the child to hospital.

Major problems from excess steroids were confined to infancy. Glucocorticoid excess was the probable cause of fatal cardiac failure in one girl. One infant developed hypertensive heart failure and another hypernatraemic convulsions due to a combination of glucocorticoid, mineralocorticoid, and intravenous fluid excess. These two patients subsequently showed learning difficulties. A further four children developed hypertension or hypokalaemia (potassium less than $3.0 \mathrm{mmol} / \mathrm{l}$ ), or both, while receiving fludrocortisone at a dose of $200 \mu \mathrm{g}$ or more daily.

\section{LEARNING DIFFICULTIES}

Fifteen subjects were known to have learning difficulties by the end of the study period (table). All but two of these children had developed a salt losing crisis during the neonatal period. One of these two subsequently developed Rett's syndrome, and this was thought to be the major cause of her intellectual impairment, whereas the other girl received large doses of hydrocortisone replacement during infancy. One of the 13 subjects with salt losing crisis developed lipoid proteinosis with epilepsy, but in the remainder there was no reason for learning difficulties other than congenital adrenal hyperplasia. Five subjects had had one or more convulsions in association with acute illness, with hypoglycaemia in four. Of the 15 subjects affected, 13 required either remedial help in a normal school (eight children) or special schooling (five children), whereas two children were considered to have milder but significant learning difficulties by their parents and doctors. In addition to the children with Rett's syndrome and lipoid proteinosis with epilepsy, two further subjects were considered to have a handicap sufficiently severe to preclude independence in adult life.

A comparison was made of the presenting features and clinical course during the first year between the group with learning difficulties and that without. Major vomiting, poor feeding, and poor weight gain/loss were more common in the group with learning difficulties (53 v 42\%, $69 v 43 \%$, and $82 v 56 \%$ respectively) but the difference was not significant. There was no significant difference in the Prader stage of virilisation, mean initial sodium concentration (119 $v 122 \mathrm{nmol} / \mathrm{l})$ nor initial 17-hydroxyprogesterone level (374 $v 386$ $\mathrm{nmol} / \mathrm{l})$. Mean blood glucose at presentation was significantly lower in the group with learning difficulties, however: $2 \cdot 0 \mathrm{mmol} / \mathrm{l}$ in six patients $v 3.9 \mathrm{mmol} / 1$ in 13 patients $(\mathrm{p}<0.05$ using two sample $t$ test). Acute admission rates were similar during the first year, but

Congenital adrenal hyperplasia and learning difficulties: patient characteristics

\begin{tabular}{|c|c|c|c|c|c|c|c|c|}
\hline $\begin{array}{l}\text { Patient } \\
\text { No }\end{array}$ & Sex & $\begin{array}{l}\text { Age on } \\
1 \text { fanuary } \\
1988 \\
\text { (years) }\end{array}$ & $\begin{array}{l}\text { Salt } \\
\text { wasting } \\
\text { disorder }\end{array}$ & $\begin{array}{l}\text { Salt } \\
\text { losing } \\
\text { crisis }\end{array}$ & $\begin{array}{l}\text { Educational } \\
\text { needst }\end{array}$ & $\begin{array}{l}\text { Assessment } \\
\text { of } \\
\text { impairment }\end{array}$ & $\begin{array}{l}\text { Additional } \\
\text { disorder }\end{array}$ & Comments \\
\hline 1 & $\mathbf{M}$ & $11 \cdot 1$ & $\mathbf{Y}$ & $\mathbf{Y}$ & $S$ & Severe & $\begin{array}{l}\text { Congenital } \\
\text { glaucoma }\end{array}$ & $\begin{array}{l}\text { Salt losing crisis at } 11 \text { days. Very ill on admission, sodium } 100 \\
\text { mmol/h, potassium } 7.8 \mathrm{mmol} / \mathrm{l} \text {, glucose } 1.6 \mathrm{mmol} / \mathrm{l} \text {. No other } \\
\text { major incidents }\end{array}$ \\
\hline 2 & $\mathbf{M}$ & $18 \cdot 9$ & $\mathrm{Y}$ & $\mathbf{Y}$ & $S$ & Severe & - & $\begin{array}{l}\text { Salt losing crisis at } 21 \text { days. Sodium } 110 \mathrm{mmol} / \mathrm{l} \text {, potassium } 8.6 \\
\mathrm{mmol} / \mathrm{h} \text {. No metabolic problems since }\end{array}$ \\
\hline 3 & F & $16 \cdot 1$ & $Y$ & $\mathbf{N}$ & $S$ & Severe & Rett's syndrome & $\begin{array}{l}\text { Developmental regression from } 18 \text { months onwards with epilepsy } \\
\text { (grand mal and drop attacks) }\end{array}$ \\
\hline 4 & $\mathbf{M}$ & $15 \cdot 4$ & $\mathrm{Y}$ & $\mathbf{Y}$ & $\mathbf{R}$ & Moderate & - & $\begin{array}{l}\text { Salt losing crisis with hypoglycaemia at } 43 \text { days. Overtreated with } \\
\text { steroids and convulsed with sodium of } 173 \mathrm{mmol} / \mathrm{l} \text { on day } 65\end{array}$ \\
\hline 5 & $\mathbf{M}$ & $14 \cdot 6$ & $\mathbf{Y}$ & $\mathbf{Y}$ & $\mathbf{R}$ & Moderate & - & $\begin{array}{l}\text { Salt losing crisis at } 12 \text { days (sodium } 114 \mathrm{mmol} / \mathrm{h} \text {, potassium }>10 \\
\text { mmol). No problems since }\end{array}$ \\
\hline 6 & $\mathbf{F}$ & $17 \cdot 4$ & $\mathbf{Y}$ & $\mathbf{Y}$ & $S$ & Moderate & - & $\begin{array}{l}\text { Salt losing crisis at } 8 \text { days (sodium } 127 \mathrm{mmol} / / \text {, potassium } 7 \cdot 9 \\
\text { mmol//). Developed hypertensive heart failure due to gross steroid } \\
\text { excess in neonatal period }\end{array}$ \\
\hline 7 & $\mathbf{M}$ & $14 \cdot 6$ & $\mathbf{Y}$ & $\mathbf{Y}$ & $\mathbf{R}$ & Moderate & $\begin{array}{l}\text { Coarctation } \\
\text { of aorta }\end{array}$ & $\begin{array}{l}\text { Presented at } 9 \text { days with salt losing crisis (sodium } 116 \mathrm{mmol} / \mathrm{l} \text {, } \\
\text { potassium } 7 \cdot 1 \mathrm{mmol} / \mathrm{l} \text { ). Developed heart failure requiring an } \\
\text { operation during neonatal period. Two admissions (one with } \\
\text { hypoglycaemia) subsequently }\end{array}$ \\
\hline 8 & $\mathbf{M}$ & $18 \cdot 9$ & $\mathrm{Y}$ & $\mathbf{Y}$ & $\mathbf{N}$ & Mild & - & $\begin{array}{l}\text { Salt losing crisis at } 9 \text { days (sodium } 123 \mathrm{mmol} / \mathrm{h} \text {, potassium greater } \\
\text { than } 8 \mathrm{mmol} / \mathrm{l} \text { ). Hypogycaemic convulsions in infancy with acute } \\
\text { illness. Four admissions in infancy and } 16 \text { subsequently }\end{array}$ \\
\hline 9 & $\mathbf{M}$ & $17 \cdot 6$ & Y & Y & $\mathbf{R}$ & Mild & - & $\begin{array}{l}\text { Salt losing crisis at } 15 \text { days (sodium } 112 \mathrm{mmol} / \mathrm{l} \text {, potassium } 6 \cdot 8 \\
\text { mmol/h). Three admissions in infancy and seven subsequently. } \\
\text { Hypglycaemic convulsion aged } 4 \text { years }\end{array}$ \\
\hline 10 & $\mathrm{~F}$ & $9 \cdot 4$ & $\mathbf{Y}$ & $\mathbf{Y}$ & $\mathbf{R}$ & Mild & - & $\begin{array}{l}\text { Salt losing crisis at } 15 \text { days (sodium } 109 \mathrm{mmol} / 1 \text {, potasium } 6.4 \\
\text { mmol/1). One admission in infancy and six subsequently (three } \\
\text { with hypoglycaemic fits) }\end{array}$ \\
\hline 11 & $\mathbf{M}$ & $14 \cdot 6$ & Y & $\mathbf{Y}$ & $\mathbf{N}$ & Mild & - & $\begin{array}{l}\text { Salt losing crisis at } 7 \text { days (sodium } 115 \mathrm{mmol} / / \text {, potassium }>7 \\
\text { mmol/1). Two admissions with hypoglycaemic convulsions }\end{array}$ \\
\hline 12 & $\mathrm{~F}$ & $14 \cdot 2$ & $\mathbf{Y}$ & $\mathbf{Y}$ & $\mathbf{R}$ & $\begin{array}{l}\text { Mild- } \\
\text { moderate }\end{array}$ & - & $\begin{array}{l}\text { Salt losing crisis day } 12 \text {. Four admissions (one convulsion). } \\
\text { Numerous urinary tract infections }\end{array}$ \\
\hline 13 & $\mathrm{~F}$ & 8.7 & $\mathbf{Y}$ & $\mathbf{N}$ & $\mathbf{R}$ & $\begin{array}{l}\text { Mild- } \\
\text { moderate }\end{array}$ & - & $\begin{array}{l}\text { Received } 60-120 \mathrm{mg} / \mathrm{m}^{2} / \text { day hydrocortisone replacement during } \\
\text { infancy }\end{array}$ \\
\hline 14 & $\mathrm{~F}$ & 10.9 & $\mathbf{Y}$ & $\mathbf{Y}$ & $\mathbf{R}$ & $\begin{array}{l}\text { Mild- } \\
\text { moderate }\end{array}$ & $\begin{array}{l}\text { Lipoid } \\
\text { proteinosis } \\
\text { and epilepsy }\end{array}$ & $\begin{array}{l}\text { Salt losing crisis at } 22 \text { days (sodium } 105 \mathrm{mmol} / \mathrm{l} \text {, potassium } 5 \cdot 7 \\
\text { mmol/1). Two admissions precipitated by fludrocortisone } \\
\text { withdrawal, one with hypoglycaemic convulsion }\end{array}$ \\
\hline 15 & $\mathbf{M}$ & $5 \cdot 8$ & Y & $\mathbf{Y}$ & $\mathbf{R}$ & Mild & - & $\begin{array}{l}\text { Salt losing crisis at } 11 \text { days (sodium } 119 \mathrm{mmol} / \mathrm{l} \text {, potassium } 7 \cdot 2 \\
\text { mmol/h, glucose } 1 \cdot 7 \mathrm{mmol} / \mathrm{\text { }} \text {. Three admissions in infancy and } 10 \\
\text { subsequently with decompensation }\end{array}$ \\
\hline
\end{tabular}


significantly higher thereafter in the group with learning difficulties $(p<0 \cdot 01)$. Convulsions due to documented hypoglycaemia were significantly more common in the group with learning difficulties, seven convulsions occurring in four patients $v$ one convulsion in one patient $(p<0 \cdot 01)$. The mean (SD) height SD score at one year was significantly worse in the group with learning difficulties: $-2 \cdot 8(1 \cdot 3) v$ $-1.7(1.2)(p<0.05)$.

\section{Discussion}

This retrospective study covers a 20 year period during which numerous changes in the diagnosis and management of congenital adrenal hyperplasia took place. We therefore need to highlight those features which are relevant to the modern management of this disorder. Although death from salt losing crisis did not occur after 1975, problems such as gender misassignment, delay in starting treatment, and failure to prevent acute decompensation and detect hypoglycaemia during acute illness all occurred in the 1980s.

Serious electrolyte derangement, which occurred in nearly half the girls in this series, could be prevented by careful monitoring of plasma sodium and potassium in suspect patients with ambiguous genitalia. Treatment should be started promptly when potassium increases as this precedes the decrease in sodium. ${ }^{10}$ We believe that gender misassignment, which occurred as late as 1985 in this study, can be minimised but not eliminated by vigilance of medical staff, urgently investigating apparent boys with bilateral cryptorchidism with or without hypospadias. Salt losing crisis in the male child can only be prevented by neonatal screening. When the diagnosis of congenital adrenal hyperplasia is made in a sick neonate, large doses of glucocorticoid are hazardous, and it is our practice to give an intravenous infusion of no more than 1 or $2 \mathrm{mg}$ hydrocortisone each hour, together with glucose and saline. When the child is sufficiently well treatment by mouth with fludrocortisone and maintenance hydrocortisone is substituted, as recommended by Hughes. ${ }^{11}$

This series records a high incidence of acute admissions in the salt wasting group with a relatively high incidence of convulsions $(7 \%)$. Approximately $10 \%$ of children had hypoglycaemia on admission, but as blood glucose was measured in barely a quarter the true incidence was presumably much higher. To prevent acute adrenal decompensation we constantly reiterate to the families the need to increase the dose of glucocorticoid in all but the mildest intercurrent illness. The higher dose of hydrocortisone is doubled and given three times each day. We also teach families to inject 50 or 100 mg hydrocortisone phosphate intramuscularly whenever the child is particularly unwell or has vomiting and diarrhoea, and it is of note that no convulsions occurred in the 38 admissions in whom this procedure was followed.

The most striking finding in this study is the high incidence of learning difficulties. Only crude measures of intellectual impairment such as the need for special educational help could be used in such a retrospective study and it is likely that with more sophisticated analysis the yield would have been even higher. Although unrelated disorders could account for learning difficulties in two of the children, there was no reason to suspect a cause other than complications of congenital adrenal hyperplasia in the remainder. We therefore conclude that the relation between learning difficulties and salt wasting 21-hydroxylase deficiency is genuine, but we have been unable to find comparable reports, though subsequent experience in the west of Scotland has been similar (Donaldson, personal observation). Thilen and Larsson found only two instances of neurological handicap in a series of 150 patients between 1969 and $1986,{ }^{3}$ whereas earlier studies have indicated an increased IQ in subjects with the disorder, though boys with salt wasting disease were underrepresented in the population studied. ${ }^{12}$ Nass and Baker have shown that children with salt wasting disease have a lower IQ (104 $v 117)$ than simple virilisers, ${ }^{13}$ but the severity of intellectual impairment in our study seems much greater. This may reflect the advantages of studying a cohort taken from a geographically defined area, rather than patients from one or more hospitals.

The learning impairment seen in this study may have been due to a variety of factors occurring in the early years. These could include metabolic derangement from the initial salt losing crisis, adrenal decompensation from acute illness, and over treatment with glucocorticoid and mineralocorticoid. Comparison between children with and without learning difficulties showed that the impaired group tended to be more symptomatic at presentation, with significantly lower initial blood glucose values, more common acute admissions after infancy, a higher incidence of hypoglycaemic convulsions, and poorer growth during the first year. The salt losing crisis was the only significant adverse event in the two most handicapped children in this study. We believe that the intellectual outcome in 21hydroxylase deficiency should be studied prospectively, and that the contribution of the salt losing crisis should be examined by carrying out neonatal screening in one or more large regions of the United Kingdom, comparing the children with matched controls and with affected subjects from other regions not practising screening. The findings of such a study might add weight to the argument for the institution of a national screening programme which would also serve to limit the physical and psychological handicap of the simple virilising variety of this disorder.

We gratefully acknowledge the patient cooperation of all paediatricians, within and outside the South West Region of England, without whom this study could not have been carried out. We also thank Karen Lance and Elizabeth Church for their help in typing the manuscript.

1 Wilkins L, Lewis RA, Klein R, et al. Treatment of congenital adrenal hyperplasia with cortisone. $₹$ Clin Endocrinol Metab 1951; 11: 1-25.

2 Brook CGD, Zachmann M, Prader A, et al. Experience with long term therapy in congenital adrenal hyperplasia. 7 Pediatr 1974; 85: 12-9. 
3 Thilen A, Larsson A. Congenital adrenal hyperplasia in Sweden 1969-1986. Prevalence, symptoms and age at diagnosis. Acta Paediatr Scand 1990; 79: 168-75.

4 DiMartino-Nardi J, Stoner E, O'Connell A, et al. The effect of treatment on final height in classical congenital adrenal hyperplasia. Acta Endocrinol (Copenh) 1986; 279 (suppl): 305-14.

5 Klingensmith GJ, Garcia SC, Jones HW, et al. Glucocorticoid treatment of girls with congenital adrenal hyperplasia: effects on height, sexual maturation and ferhyperplasia: effects on height, sexual

6 Hurtig AL, Rosenthal IM. Psychological findings in early treated cases of female pseudohermaphroditism caused by virilizing congenital adrenal hyperplasia. Arch Sex Behav 1987; 16: 209-23.

7 Dittmann RW, Kappes ME, Kappes MH. Sexual behaviou in adolescent and adult females with congenital adrenal hyperplasia. Psychoneuroendocrinology 1992; 17: 153-70.
8 Mulaikal RM, Migeon CJ, Rock JA. Fertility rates in female patients with congenital adrenal hyperplasia due to 21 hydroxylase deficiency. $N$ Engl $₹$ Med 1987; 316: 178-82.

9 Prader A. Der Genitalbefund bein Pseudohermaphroditismus feminus des kongenitalen adrenogenitalen ditismus feminus des kongenitalen adrenogenitalen

10 Brook CGD. The management of clasical 231-43. adrenal hyperplasia due to 21 -hydroxylase deficiency. Clin Endocrinol 1990; 33: 559-67.

11 Hughes IA. The adrenal gland. In: Hughes IA, ed. Handbook of endocrine investigations in children. London: Handbook of endocrine inves

12 Money J, Lewis V. IQ genetics and accelerated growth: adrenogenital syndrome. fohns Hopkins Hospital Bulletin 1966; 118: 365-73.

13 Nass R, Baker S. Learning disabilities in children with congenital adrenal hyperplasia. $f$ Child Neurol 1991; 6: 306-12.

\section{Is alternating hemiplegia a mitochondrial disease?}

The syndrome of alternating hemiplegia of childhood (AHC) was first described in $1971^{1}$ and has usually been thought to be a variant of migraine. A recent report from Paris describes 22 children and is an excellent review of the clinical findings and differential diagnosis. ${ }^{2}$ The cardinal features are: (1) repeated episodes of hemiplegia affecting each side of the body in turn, and sometimes both together, and occurring at least once a month; (2) onset before the age of 18 months; (3) recovery from hemiplegia during sleep; (4) paroxysmal dystonia, nystagmus, and autonomic disturbance; and (5) non-paroxysmal choreoathetosis, ataxia, and global learning disorder. The French workers point out that some of the features of AHC are similar to those of MELAS (mitochondrial myopathy, encephalopathy, lactic acidosis, and stroke-like episodes) a known mitochondrial disorder.

A paper from Montreal (Douglas L Arnold and colleagues, Annals of Neurology 1993; 33: 604-7) provides evidence of mitochondrial dysfunction in AHC. They examined four children with the disease using magnetic resonance spectroscopy to measure phosphorus and its compounds in resting gastrocnemius muscle and found reduced phosphorylation potential (a measure of mitochondrial energy storage ability (as ATP)), reduced amounts of phosphocreatine, and increased amounts of inorganic phosphate and ADP.

The authors interpret their findings as indicating mitochondrial dysfunction in muscle. They state that they can not be sure whether this dysfunction is primary or secondary but suggest that the clinical features of AHC taken together with these findings are consistent with a primary disorder of mitochondrial function.

ARCHIVIST

1 Verret S, Steele JC. Alternating hemiplegia in childhood: a report of eight patients with complicated migraine beginning in infancy. Pediatrics 1971; 47: 675-80.

2 Bourgeois M, Aicardi J, Goutieres F. Alternating hemiplegia of childhood. $\mathfrak{f}$ Pediatr 1993; 122: 673-9. 